\title{
The multilevel inverter with clamped-diode
}

\author{
Trong-Thang Nguyen \\ Faculty of Energy Engineering, Thuyloi University, Vietnam
}

\begin{tabular}{l}
\hline Article Info \\
\hline Article history: \\
Received Nov 20, 2018 \\
Revised Jan 21, 2019 \\
Accepted Feb 27, 2019 \\
\hline
\end{tabular}

Keywords:

AC voltage

Inverter

Multilevel

\begin{abstract}
In this study, the author analyzes the advantages and disadvantages of multilevel inverter compared to the traditional two-level inverter and then chose the suitable inverter. Specifically, the author analyzes and designs the threelevel inverter, including the power circuit design and control circuit design. All designs are verified through the numerical simulation on Matlab. The results show that even though the three-level inverter has a low number of switches (only 12 switches), but the quality is very good: the total harmonic distortion is small; the output voltage always follows the reference voltage.
\end{abstract}

Corresponding Author:

Trong-Thang Nguyen,

Faculty of Energy Engineering,

Thuyloi University,

Vietnam, 175 Tay Son, Dong Da, Hanoi, Vietnam.

Email: nguyentrongthang@ @lu.edu.vn

\section{INTRODUCTION}

In the production process, the motion drive system plays an important role which greatly affects the quality of the product. The most common electric-motor used in motion systems is the Alternating Current Motor (AC-Motor) [1-2] because of its advantages. To control the torque and speed of the three-phase AC motor, the grid voltage is not supplied directly to the AC-Motor but supplied indirectly to the AC-Motor through a converter [3]. This converter will change both the frequency and the voltage supplied to the ACMotor so that the speed, torque of the AC-Motor reaches the desired values. The converter consists of two parts: the rectifier [4] and the inverter [5-6]. The inverter is responsible for controlling the speed of the motor exactly and reduces the electric-loss.

There are two types of inverter: the two-level inverter [7] and the multi-level inverter [8]. For example, the two-level inverter is shown in Figure 1, this is a three-phase inverter with two levels of voltage. The downside of the two-level voltage inverters is that the slope of the voltage supplied to the motor is large, so it damages the rotating part and reduces the insulation of the motor. The high-frequency switching reduces the norm of parameters, reduces the life of the circuit and increases the power loss.

To overcome the disadvantages mentioned above, the multi-level inverters are researched and developed to replace the two-level inverters. The advantages of using the multi-level inverters [9] are as follows: Improving the power [10-11]; the reduction of the switching frequency makes the loss reduction of components; the high-order harmonic components of the output voltage are smaller. Therefore, in this study, the author will focus on the analysis and construction of multi-level inverters that meet the high goal of output voltage quality. The results will be demonstrated through the numerical simulation on Matlab. 


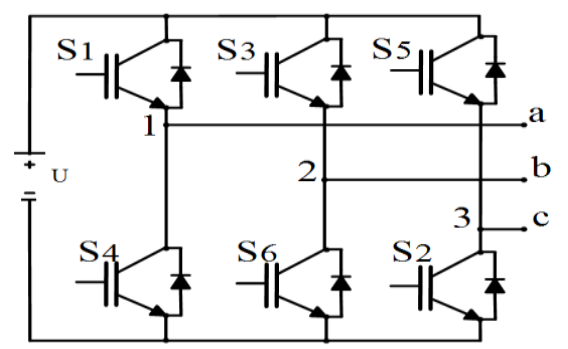

Figure 1. The two-level inverter

\section{THE STRUCTURE OF THE MULTI-LEVEL INVERTER}

A multi-level inverter consists of the following components:

a) The power circuit is composed of semiconductor components: the Insulated Gate Bipolar Transistor (IGBT) and other auxiliary components (capacitor, diode). The input of the power circuit is connected to the DC source. The output can be connected directly to the load (AC-Motor), or indirectly through the filter. The control signals are supplied from the controller.

b) The controller of multi-level pulse executes the defined-rule to on/off the semiconductor switch. The input signal fed into the controller is the desired voltage (or current). Then, the controller calculates, processes to generate the pulse signals to control the semiconductor valves. The structure of the multilevel inverter as shown in Figure 2.

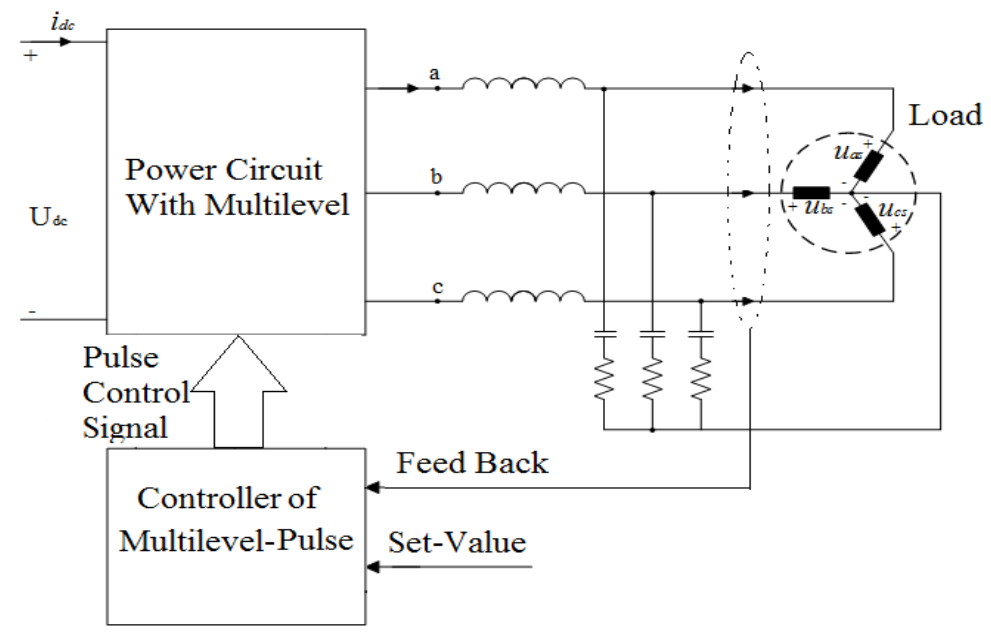

Figure 2. The structure of the multi-level inverter

For example, in the case of the two-level inverter, the output voltage consists of two values of 0 and $\mathrm{U}$. In the case of the three-level inverter, the output voltage consists of three values of $0, \mathrm{U}$ and $2 \mathrm{U}$. Similarly, it is possible to determine the number of the output voltage level of the five-level inverter, the nine-level inverter.

One of the most obvious parameters of output voltage quality is Total harmonic distortion. The higher the level number, the lower the THD [12]. The highest level-number of inverters applied in practice is 9 because the nine-level inverter has given the quality of the output voltage is very high, the increase in the level number is not necessary. Moreover, it is difficult to increase the level number of voltage because of limitations in semiconductor technology and computing devices.

There are two types of the multi-level inverter, the clamped-capacitor type [13-14] is shown in Figure 3, and the clamped-diode [15] is shown in Figure 4. Compared with the clamped-capacitor model, the clamped-diode model has the advantage of having fewer switching states. Therefore, in this study, the author will analyze and build the multi-level inverter system with the clamped-diode. 


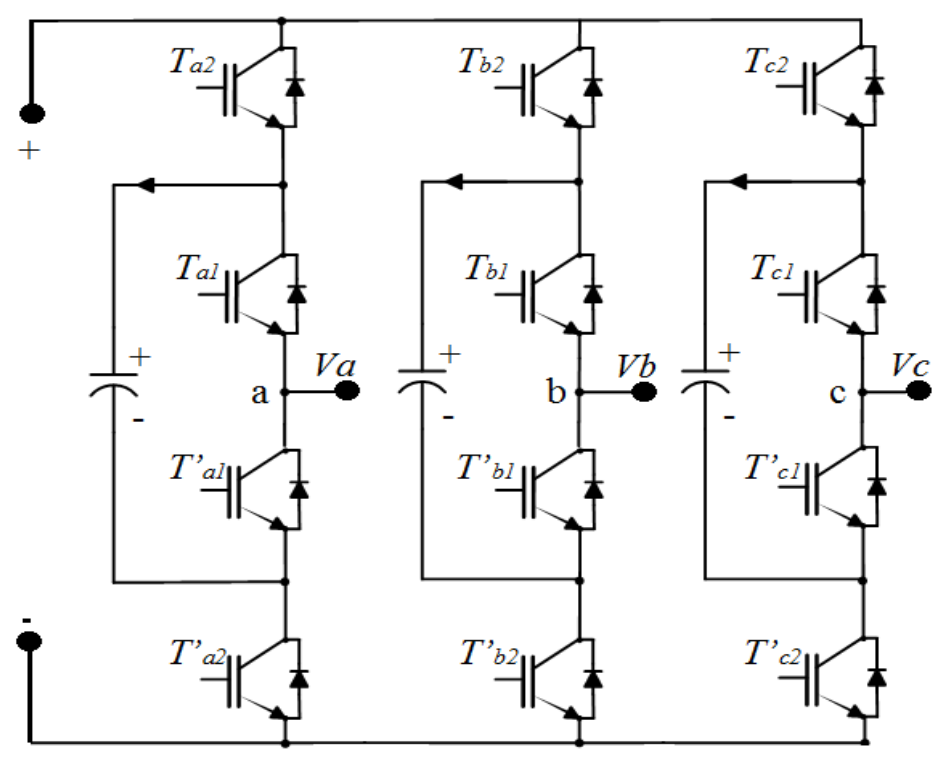

Figure 3. The three-level-three-phase inverter with clamped-capacitor

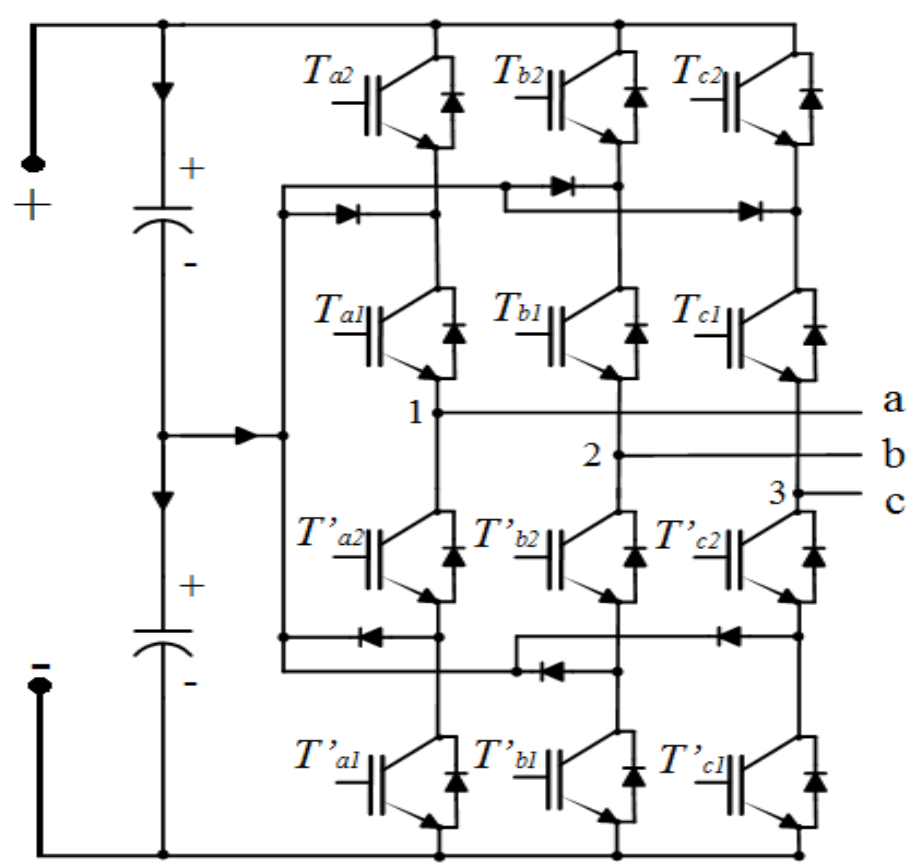

Figure 4. The three-level-three-phase inverter with clamped-diode

\section{BUILDING THE SYSTEM OF THE THREE-LEVEL-THREE-PHASE INVERTER WITH CLAMPED-DIODE}

On the basis of the clamped-diode inverter model shown in session 2, in this part, the author builds the model of the three-level-three-phase inverter in order to investigate and verify the quality of the system. The overall circuit diagram is shown in Figure 5.

In the power circuit consists of 12 switches, each phase consists of 4 switches. For example, in the A-phase, there are two switches that control positive branch (a2, a1) and two switches that control the negative branch (av2, av1). The control process is shown in Table 1. 


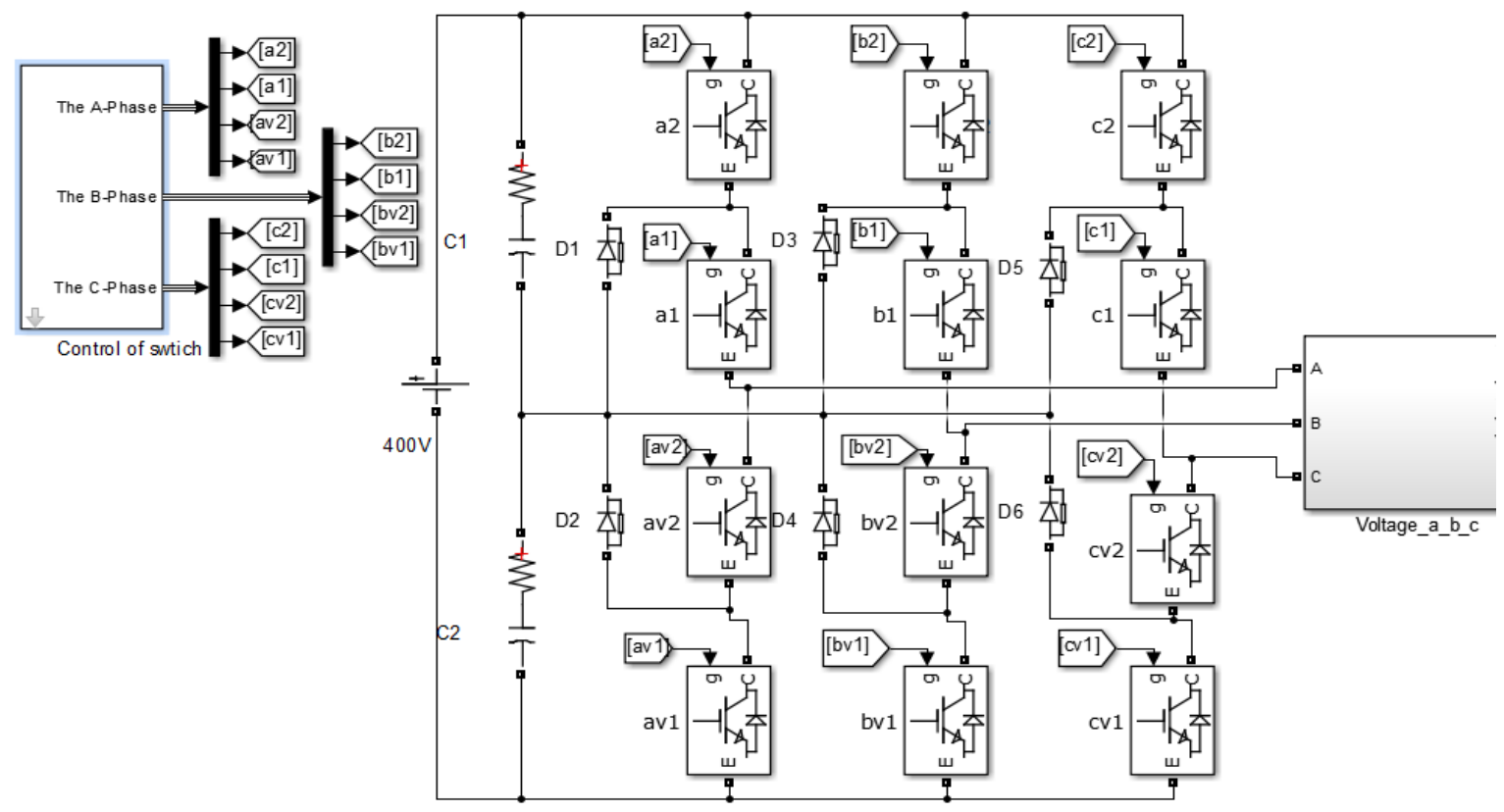

Figure 5. The overall circuit diagram

Table 1. The Control Process

\begin{tabular}{ccccc}
\hline The Status & a2 & a1 & av2 & av1 \\
\hline Vreference<Vcarrier1<Vcarrier2 & OFF & OFF & ON & ON \\
Vcarrier1 $<$ Vreference $<$ Vcarrier2 & ON & OFF & OFF & ON \\
Vcarrier1<Vcarrier2 $<$ Vreference & ON & ON & OFF & OFF \\
\hline
\end{tabular}

The block diagram of the control of switch is shown in Figure 6. It includes three control blocks of the phase A, B, C. The inputs of each control block include a reference signal and two carrier signals. The outputs of each control block consist of two positive control pulses and two negative control pulses. These output pulse signals must perform the processes according to Table 1. For example, the detailed diagram of the control of the A-phase is shown in Figure 7, and the signals are shown in Figure 8.

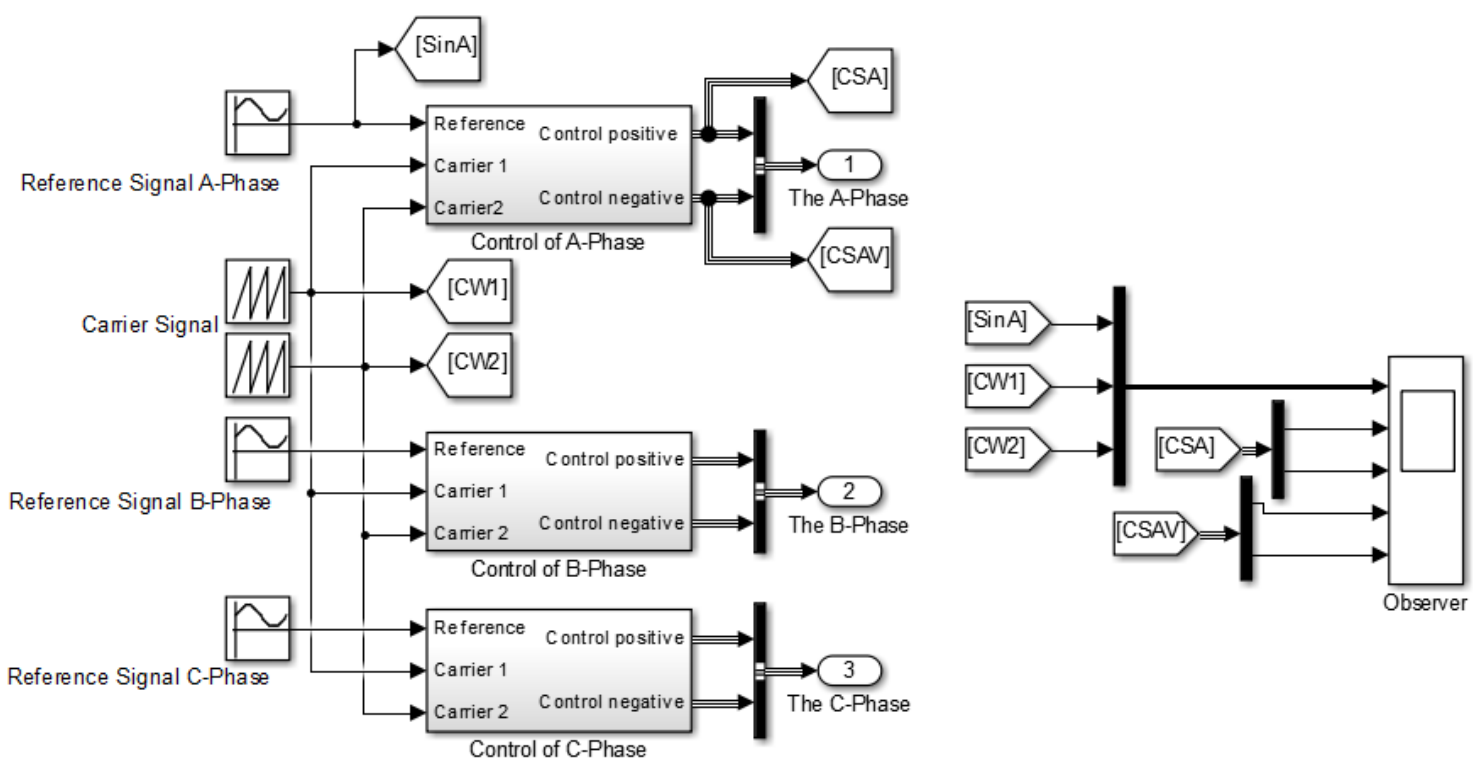

Figure 6. The block diagram of the control of switch 


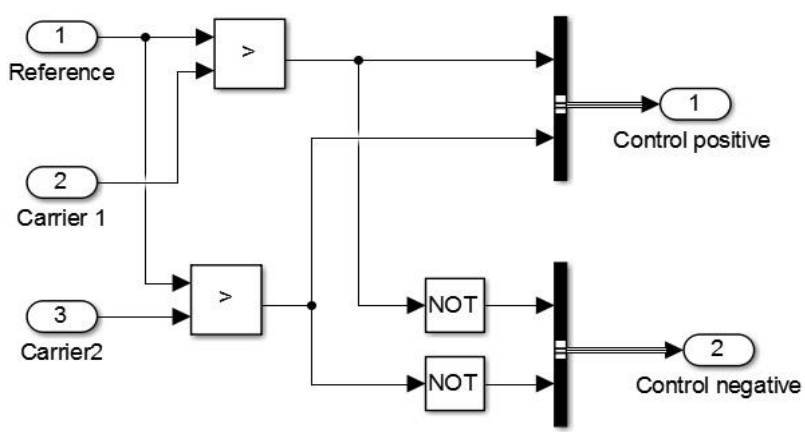

Figure 7. The detailed diagram of the control of A-phase
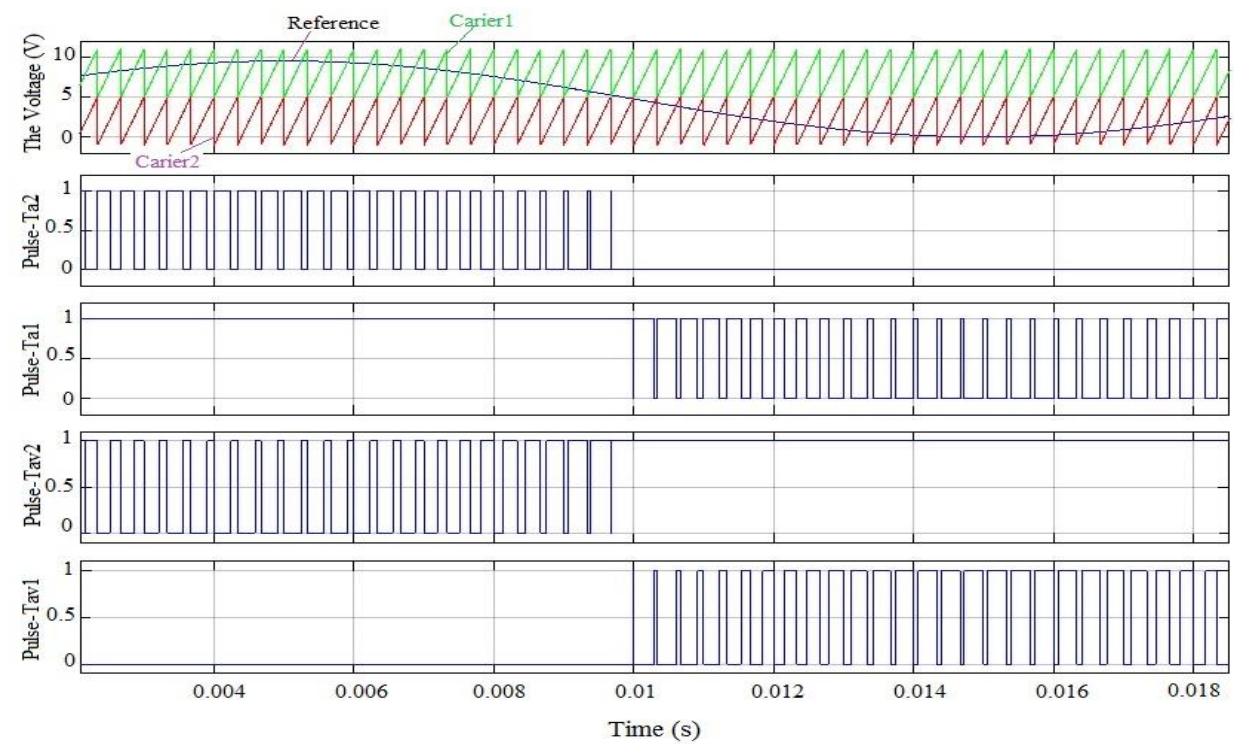

Figure 8. The control signals of the A-Phase

\section{THE SIMULATION RESULTS AND ANALYSIS}

Running the model built in part 3, we get the results as follows: The wire voltage signals are shown in Figure 9; The voltage quality is shown through THD and is shown in Figure 10.

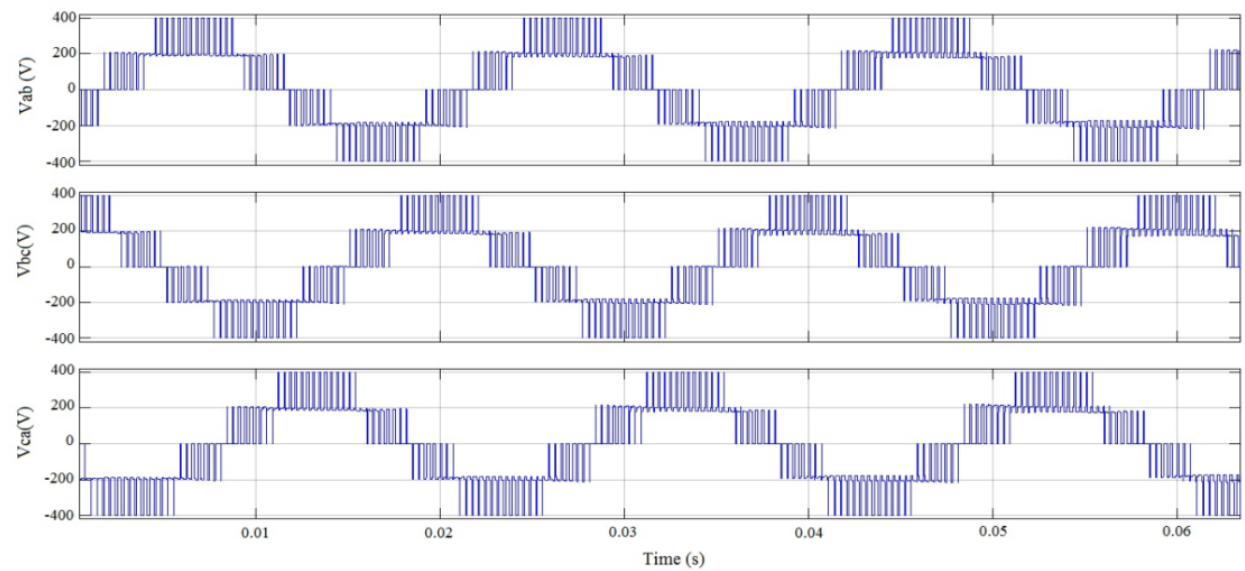

Figure 9. The wire voltages 


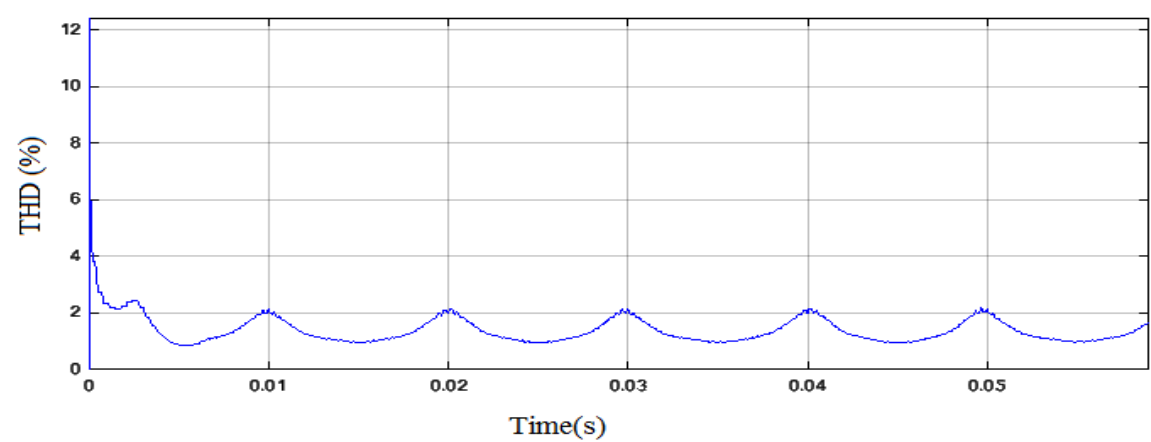

Figure 10. THD of the wire voltage

From the THD result of output wire voltage shows that THD $<2 \%$, so the output wire voltage has been good quality. The results of the phase-voltages are shown in Figure 11. To improve the phase-voltage quality, we set the phase voltages through the filter, the results are shown in Figure 12.

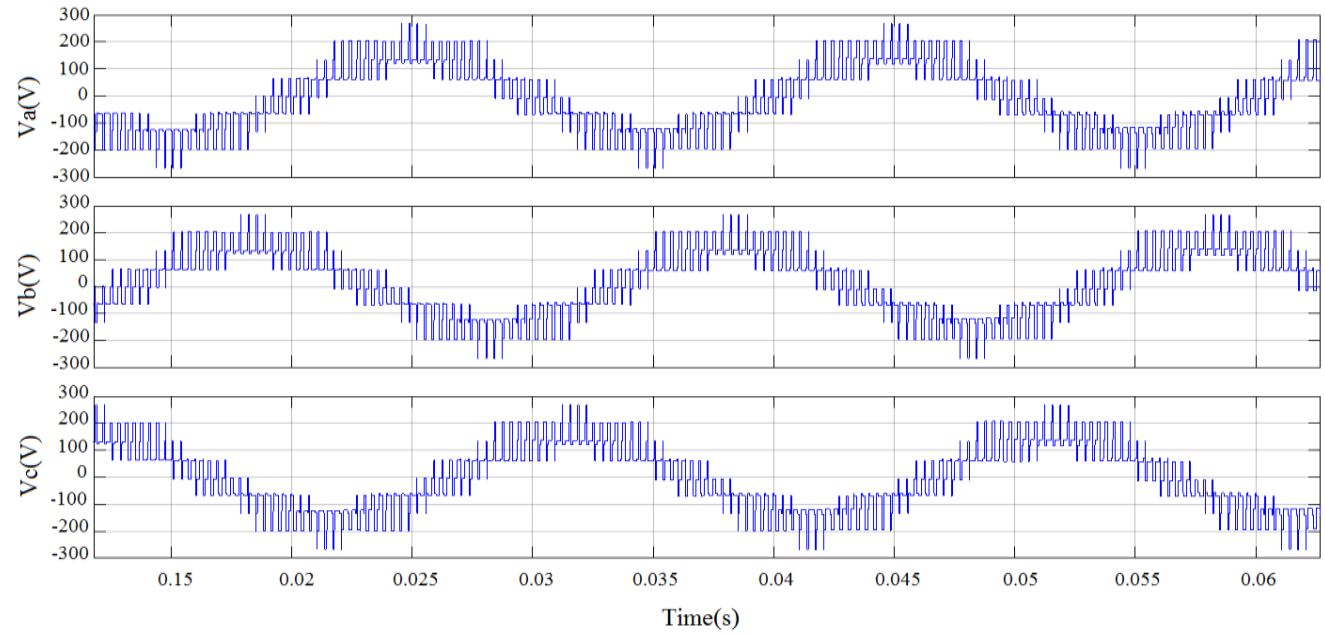

Figure 11. The phase-voltages

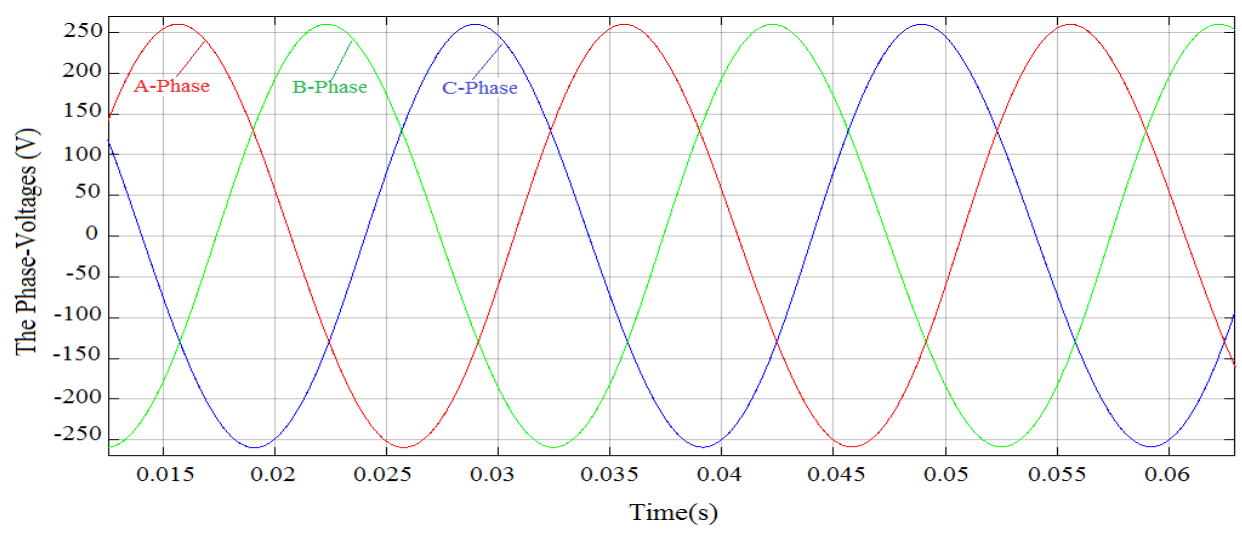

Figure 12.The phase-voltages after the filter

The output voltages of the multi-level inverter have been of high quality, the THD is small $(<2)$, so this inverter can meet the requirements in practice. 


\section{CONCLUSION}

In this study, the author shows the advantages of multi-level inverter compared to the traditional two-level inverter. However, in the case of a large number of the level, the high technology, and the high production cost will be required. Therefore, the author proposed and built the three-level inverter, which is the appropriate number of levels, leading to the number of switches in the system is not too large. The result is that the output voltage of the inverter has good quality, the THD is small. The shape of the output voltage always follows the shape of the reference voltages. So, this is the inverter which meets both economic and technical requirements in practice.

\section{REFERENCES}

[1] Abdelhak, B., \& Bachir, B. A High gain observer based sensorless nonlinear control of induction machine. International Journal of Power Electronics and Drive Systems (IJPEDS), 5(3), 305, 2015.

[2] Gunabalan, R., \& Subbiah, V. Speed Sensorless Vector Control of Induction Motor Drive with PI and Fuzzy Controller. International Journal of Power Electronics and Drive Systems (IJPEDS), 5(3), 315, 2015.

[3] Ramesh, A., Sekhar, O. C., \& Kumar, M. S. (2018). A Novel Three Phase Multilevel Inverter with Single Dc Link For Induction Motor Drive Applications. International Journal of Electrical and Computer Engineering (IJECE), 8(2), 763-770.

[4] Glorot, X., Bordes, A., \& Bengio, Y. (2011, June). Deep sparse rectifier neural networks. In Proceedings of the fourteenth international conference on artificial intelligence and statistics (pp. 315-323).

[5] Ramesh, A., Sekhar, O. C., \& Kumar, M. S. (2018). A Novel Three Phase Multilevel Inverter with Single Dc Link For Induction Motor Drive Applications. International Journal of Electrical and Computer Engineering (IJECE), 8(2), 763-770.

[6] Habbab, M., Hazzab, A., \& Sicard, P. (2018). Real Time Implementation of Fuzzy Adaptive PI-sliding Mode Controller for Induction Machine Control. International Journal of Electrical and Computer Engineering (IJECE), 8(5).

[7] Nor Azizah Yusoff, Azziddin M. Razali, Kasrul Abdul Karim, Auzani Jidin, Tole Sutikno (2018). An Analysis of Virtual Flux Direct Power Control of Three Phase AC-DC Converter. International Journal of Power Electronics and Drive Systems (IJPEDS), 9 (3), 947-956

[8] S. Nagaraja Rao, D. V. Ashok Kumar, Ch. Sai Babu (2018). Grid Connected Distributed Generation System with High Voltage Gain Cascaded DC-DC Converter Fed Asymmetric Multilevel Inverter Topology. International Journal of Electrical and Computer Engineering (IJECE), 8(6), 4047-4059.

[9] Rodriguez, J., Lai, J. S., \& Peng, F. Z. (2002). Multilevel inverters: a survey of topologies, controls, and applications. IEEE Transactions on industrial electronics, 49(4), 724-738.

[10] Lai, J. S., \& Peng, F. Z. (1995, October). Multilevel converters-a new breed of power converters. In Industry Applications Conference, 1995. Thirtieth IAS Annual Meeting, IAS'95., Conference Record of the 1995 IEEE (Vol. 3, pp. 2348-2356). IEEE.

[11] Tolbert, L. M., \& Peng, F. Z. (1998, February). Multilevel converters for large electric drives. In Applied Power Electronics Conference and Exposition, 1998. APEC'98. Conference Proceedings 1998., Thirteenth Annual (Vol. 2, pp. 530-536). IEEE.

[12] Rodriguez, J., Lai, J. S., \& Peng, F. Z. (2002). Multilevel inverters: a survey of topologies, controls, and applications. IEEE Transactions on industrial electronics, 49(4), 724-738.

[13] Meynard, T. A., \& Foch, H. (1992). Multi-level choppers for high voltage applications. EPE journal, 2(1), 45-50.

[14] Hochgraf, C., Lasseter, R., Divan, D., \& Lipo, T. A. (1994, October). Comparison of multilevel inverters for static var compensation. In Conference Record-Ieee Industry Applications Society Annual Meeting (pp. 921-921). IEEE INC

[15] Nabae, A., Takahashi, I., \& Akagi, H. (1981). A new neutral-point-clamped PWM inverter. IEEE Transactions on industry applications, (5), 518-523. 